\title{
Comparison of Intervertebral Disc Injuries Caused By Different Diode Laser Wavelengths
}

\author{
Ferreira CCS ${ }^{1}$, Sella VR ${ }^{1}$, Bomfim FR ${ }^{1}$, Florencio-Silva R $^{2}$, Simões RS, Abdala $\mathbb{N}^{3}$, and Plapler $\mathrm{H}^{1}$
}

'Department of Surgery, Division of Operative Technique and Experimental Surgery, Universidade Federal de São Paulo [Federal University of São Paulo], Escola Paulista de Medicina - UNIFESP-EPM, São Paulo, SP, Brazil

'Department of Morphology and Genetics, Division of Histology and Structural Biology, Universidade Federal de São Paulo [Federal University of São Paulo], Escola Paulista de Medicina, UNIFESP-EPM, São Paulo, SP, Brazil

${ }^{3}$ Department of Diagnostic Imaging, Universidade Federal de São Paulo [Federal University of São Paulo], Escola Paulista de Medicina- UNIFESPEPM, São Paulo, SP, Brazil

*Corresponding author: Rinaldo Florencio-Silva Rua Botucatu, 740 - Ed. Lemos Torres, 2o andar - Vila Clementino - São Paulo - SP - Brazil, Tel: +55 1155764848 - VOIP 1112, E-mail: mjsimoes_43@hotmail.com

Rec date: October 17, 2018; Acc date: October 29, 2018; Pub date: November 3, 2018

Citation: Ferreira CCS, Sella VR, Bomfim FR, Plapler H, Silva RF, et al. (2018) Comparison of intervertebral disc injuries caused by different diode laser wavelengths Spine Res. Vol.4: No.2.

\section{Abstract}

Background: Laser discectomy or laser nucleotomy comprises an increasingly important place in less invasive spinal procedures, but the ideal laser is still a subject of study. This research was aimed to compare the action of diode laser at different wavelengths, as well as the volume of the vaporization lesion caused by the different wavelengths in the percutaneous decompression procedures of the intervertebral disc (nucleotomy).

Methods: Six pigs' lumbar columns had their intervertebral discs (region L1 to L5) underwent punctureinduced injury. The columns were then subjected to the nuclear magnetic resonance (MR) for pre-irradiation analysis. Later, the discs were irradiated with a laser at the wavelengths of $808 \mathrm{~nm}$ (G808), $980 \mathrm{~nm}$ (G980), $1470 \mathrm{~nm}$ (G1470) and $1908 \mathrm{~nm}$ (G1908), or not irradiated (Control group). The columns were then destined for MR and then immersed in $10 \%$ buffered formalin for histological analysis. After being decalcified the intervertebral discs were dissected and processed for paraffin embedding. Transverse sections of the disks were stained with hematoxylin and eosin for histomorphometry and carbonized and bubble areas were measured.

Results: The lesions were equivalent within each group and there was no difference between the groups in the pre-irradiation. In the post-irradiation evaluation, the MR showed that the volume of the intervertebral disc lesion was smaller in the $\mathrm{G} 1470$ and $\mathrm{G} 1908$ groups compared to the other groups. The G808 and G980 groups showed a higher thickness of carbonized area compared to groups G1470 and G1908. In addition, G980 presented higher thickness bubble area compared to the other groups. These lesions were more pronounced and more localized in the G808 and G980 groups, compared the $1470 \mathrm{~nm}$ and
$1908 \mathrm{~nm}$ lasers, which caused broader but less intense lesions.

Conclusion: The intervertebral disc lesions caused by the $808 \mathrm{~nm}$ and $980 \mathrm{~nm}$ laser are more intense but more focal, compared to the $1470 \mathrm{~nm}$ and $1908 \mathrm{~nm}$ laser.

Keywords: Laser discectomy; Laminectomy; Low back pain, Histology; Magnetic resonance; Pigs

\section{Introduction}

The most widely used method to correct herniated discs still consists in its withdrawal and in the settlement of the involved vertebrae through a procedure called arthrodesis, to prevent intervertebral space collapse [1]. Other less aggressive methods, such as percutaneous interventions, improve the results. These procedures can be done through the application of high frequency (HF) or laser irradiation [2].

The advantages of these alternative methods over arthrodesis include no need of hospitalization and conduction of outpatient procedures with fast resolution, as well as a reduction in the recovery time, faster treatment and rehabilitation and lower social and economic costs. In addition, in open surgery, the access to the discs is attained through the disruption of the posterior longitudinal ligament and of the fibrous annulus, which increases the re-injury probability [3].

In the last 15 years, minimally invasive surgical procedures have been replacing the conventional open surgical ones in almost all areas of medicine. The percutaneous discectomy generally attends to a class of minimally-invasive surgical procedures suggested for reducing intra-disc pressure.

One of the theories on the improvement brought by percutaneous discectomy suggests that the removal of disc material reduces the internal disc pressure, leading the 
segment back to the core center. Another relevant mechanism is that the removal of disc material can prevent the release of chemical mediators, which negatively affect the spinal nerve $\operatorname{root}[4,5]$.

The main purpose of percutaneous laser disc decompression, as a treatment for contained herniated (nonextruded) discs, is to selectively decrease the amount of the nucleus pulposus material, maintaining the adjacent tissues intact. Initially addressed only for lumbar discs treatment, the technique is also feasible for thoracic and cervical discs $[1,6]$.

Laser discectomy does not mechanically remove disc material. This is because the intervertebral disc is considered a closed hydraulic system that promotes a controlled reduction in intern disc pressure through the vaporization of the most appropriate nuclear section of the disc volume. This action leads to the retraction of the herniated part of the disc $[5,7,8]$.

The open surgery has evolved to endoscopic procedures and to percutaneous techniques with discordant results [9] Since the first percutaneous laser discectomy was performed by Choy and Ascher in 1986, the search for best results has relied upon different types of laser and more appropriate parameters to vaporize lesser amounts of liquid $[10,11]$.

The intervertebral discs are water-rich and contain few pigmented chromophores. For this reason, the ideal laser irradiation might present a high-water absorption coefficient and a low tissue pervasion, therefore limiting the adjacent tissue thermal injury.

The choice for the best kind of laser for this procedure (Nd:YAG, Ho:YAG or diode laser) is controversial [5,12-14], due to the differences among them. Most authors, however, believe that the diode laser is the most appropriate, followed by the Nd:YAG laser [8].

Plapler et al. [15] performed laser discectomy (nucleotomy) in an ex-vivo model in pigs' columns. The wavelength of 1908 $\mathrm{nm}$, power of $5 \mathrm{~W}$, and $1200 \mathrm{~J}$ dose proved to be more efficient, causing less injury and tissue breakdown than the $808 \mathrm{~nm}, 980 \mathrm{~nm}$ and $1470 \mathrm{~nm}$ laser wavelengths. They assumed that the free water contained in the tissues after the freezing/thawing process could play a role in this result. In discs to which the laser was not applied, the samples deterioration was higher. By modifying the tissue structure through water evaporation and by forming a charred tissue with lower aqueous content, the laser application lessens tissue degradation due to defrosting. This fact justifies some measurements of greater injury depth in the control group compared to the laser group. These measures may be caused by tissue deterioration, which increases the size of the lesions, but without leading to any residual damage.

Based on the current literature, this study was performed to investigate the action of the laser emission in the near infrared (808 to $1908 \mathrm{~nm}$ ) region in the context of surgical procedures for percutaneous intervertebral disc decompression (nucleotomy) in fresh pigs' columns, at room temperature.

\section{Material and Methods}

This research was approved by the Ethics Committee (4530240314). In this analytical interventional double-blind experimental study, we have used 30 discs (L1 to L5) of intervertebral spinal columns from pigs. The column segments were mounted in a support, ensuring their immobility [3]. Twenty-Gauge needles were inserted and located in the nucleus pulposus (Figure 1).

Once the nucleus pulposus is reached, a silica optical fiber with a core diameter of $400 \mu \mathrm{m}$ was introduced, keeping the fiber tip $5 \mathrm{~mm}$ beyond the tip of the needle. Then the laser $(n=26)$ with wavelengths ranging from $808 \mathrm{~nm}$ to $1908 \mathrm{~nm}$ was fired, released in pulses (lasting 1 second followed by a 1second interval), in a total of 120 pulses for the vaporization of the nucleus pulposus on a single spot of application. The total energy applied to all the discs was $1200 \mathrm{~J}$. In each column, one disc served as control, with no laser irradiation $(n=6)$ (Table 1).

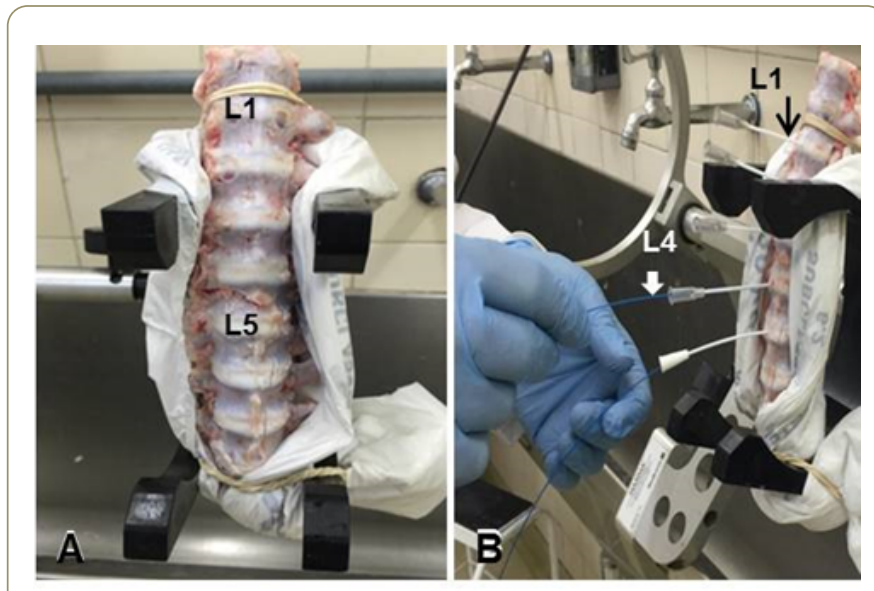

Figure $\mathbf{1}$ (A) Mounted column (B) and needle insertion.

Table 1 Laser parameters.

\begin{tabular}{|l|l|l|l|l|}
\hline \multirow{2}{*}{$\begin{array}{l}\text { Emission } \\
\text { wavelength (nm) }\end{array}$} & $\begin{array}{l}\text { Maximal } \\
\text { potency (W) }\end{array}$ & $\begin{array}{l}\text { Power } \\
\text { applied }\end{array}$ & Energy & $\begin{array}{l}\text { Laser } \\
\text { emitting }\end{array}$ \\
\cline { 3 - 5 } & $(\mathrm{W})$ & $(\mathrm{J})$ & diode \\
\hline Control & 0 & 0 & 0 & --- \\
\hline 808 & 30 & 10 & 1200 & InGaAs \\
\hline 980 & 30 & 10 & 1200 & InGaAs \\
\hline 1470 & 15 & 10 & 1200 & InGaAsP \\
\hline 1908 & 10 & 10 & 1200 & $\begin{array}{l}\text { AlGaln- } \\
\text { AsSb }\end{array}$ \\
\hline
\end{tabular}

\section{Nuclear Magnetic Resonance (MR)}

The vertebral columns were evaluated before and after laser irradiation in a Magneton Skyra 3T device (Siemens Medical Solutions, Erlangen, Germany) equipped with a $45 \mathrm{mT} / \mathrm{m}$ gradient system. The images were acquired with a 16-channel handle coil with 16 integrated amplifiers. For that purpose, the sagittal and axial plans were cut, to evaluate the injured sites. 
Thus, the lesions were classified as Type I - Linear with rupture of the fibrous annulus and nucleus pulposus; Type II Expanded but restricted to the disk compromising up to $25 \%$ of the disk; Type III - Expanded but restricted to the disk compromising more than $25 \%$ of the disk; Type IV - Expanded disc, associated with bone involvement.

MR parameters were as follows: sagittal plane: T2-SPC sequence acquisitions had the following characteristics: TR/ $\mathrm{TE}=1000 / 134$ milliseconds; $\mathrm{FOV}=120 \times 140 \mathrm{~mm}$; matrix size $=384 \times 332$; performing cuts with thickness of $0.5 \mathrm{~mm}$; without gaps between cuts. Number of averages and bandwidth $=280 \mathrm{hz} /$ pixel.

To ensure correct orientation, sagittal and coronal sequences were used. Acquisition time of 3 minutes and 33 seconds. Axial plane: aligned with the plane of the intervertebral disc. Sequential T1 with inversion/Turbo spin echo recovery: $\mathrm{TR} / \mathrm{TE} / \mathrm{TI}=2,400 / 15 / 100$ milliseconds, $\mathrm{FOV}=112$ $\times 200 \mathrm{~mm}$; matrix size $=256 \times 118 ; 5$ cuts per vertebral level with $3 \mathrm{~mm}$ thickness; cut-off interval of $3.6 \mathrm{~mm}$; number of averages: 1; bandwidth $=190 \mathrm{hz} /$ pixel. Acquisition time of 5 minutes and 36 seconds.

\section{Morphological and histomorphometrical analyzes}

All discs were kept in $10 \%$ buffered formalin until their preparation for the microscopic examination to assess the changes generated by the different laser wavelengths. We have rated the pervasion depth and the quality of the tissue injured by the laser shots in the remaining tissue and the kind of injury induced by this action. The discs were fixed in phosphate-buffered $10 \%$ formalin, decalcified in a solution of $20 \%$ formic acid buffered with sodium citrate, and processed for paraffin embedding.

Transverse histological sections $(4 \mu \mathrm{m})$ were stained with hematoxylin-eosin (H.E) and observed in an optical microscopy (Axio Lab A1, Carl Zeiss), attached to a high-resolution camera (AxioCam ICc5, Carl Zeiss) to determine the lesion depth and the thermal damage. For histomorphometric analysis, all fields of carbonized and bubble areas were captured. Subsequently, by using a software program (AxionVision SE64 Rel.4.9.1), the thickness of carbonized and bubble areas were measured (in $\mu \mathrm{m})$, as previously described [16]; then, a mean value for each animal and subsequently for each group was calculated.

\section{Statistical analysis}

Statistical analyses were carried out using the GraphPad Prism 5 software (GraphPad Software, Inc., San Diego, CA). It was used the non-parametric test of Kruskal-Wallis to compare all the groups and the Mann-Whitney test (one-side) to compare the control group to laser groups. Data were expressed as mean \pm standard deviation (SD) and statistical significance was set at $p \leq 0.05$.

\section{Results}

\section{Nuclear Magnetic Resonance (NMR)}

The analysis of the images captured by MR showed lesions of the discs, which varied in shape and extension according to the different wavelengths used. These lesions present a single and/or multiple ablation appearance and were located at the periphery of the intervertebral discs. These were of less extension with the irradiation's of $1470 \mathrm{~nm}$ and $1908 \mathrm{~nm}$ when compared to $808 \mathrm{~nm}$ and $980 \mathrm{~nm}$ (Figure 2).
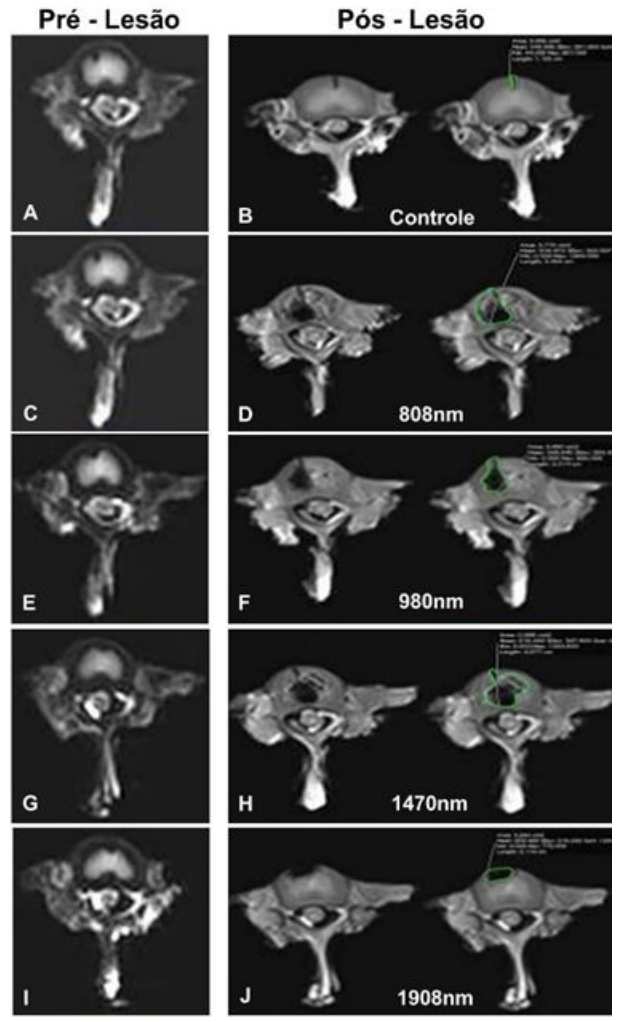

Figure 2 Intervertebral discs before (Column 1) and after (Column 2) laser irradiation. Line $1(A$ and $B)=$ Control, line 2 $(C, D)=808 \mathrm{~nm}$, line $3(E, F)=980 \mathrm{~nm}$, line $4(G, H)=1470 \mathrm{~nm}$ and line $5(\mathrm{I}, \mathrm{J})=1908 \mathrm{~nm}$

The volumes (mean+SD) of the lesions were $0.0033+0.0387$ (control), $0.0436+0.0371$ (G1908), 0.1423+0.1092 (G1470), $0.2433+0.0720$ (G980) and 0.2305+0.1505 (G808) (Table 2).

\section{Morphological and histomorphometric analysis}

Histological analysis showed carbonized regions and bubble areas in all irradiated groups. However, these regions were more evident in the groups submitted to the laser with the wavelength of $808 \mathrm{~nm}$ and $980 \mathrm{~nm}$, compared to the laser with the wavelength of $1470 \mathrm{~nm}$ and $1908 \mathrm{~nm}$ (Figure 3). The histomorphometric analysis showed that the thickness of the carbonized area was significantly higher $(p<0.05)$ in $\mathrm{G} 808$ and G980, when compared to the other groups. In addition, the 
G980 presented the higher thickness $(p<0.05)$ of the bubble area, as compared to the other groups (Figure 4).

Table 2 Volume variation $\left(\mathrm{mm}^{3}\right)$ measured through MR.

\begin{tabular}{|c|l|l|l|l|l|}
\hline \multirow{7}{*}{} & $\mathbf{C t r l}$ & $\mathbf{G 8 0 8}$ & $\mathbf{G 9 8 0}$ & $\mathbf{G 1 4 7 0}$ & $\mathbf{G 1 9 0 8}$ \\
\cline { 2 - 6 } & -0.0102 & 0.4821 & 0.1188 & 0.0897 & -0.0138 \\
\cline { 2 - 6 } & 0.0867 & 0.0471 & 0.3054 & 0.1917 & 0.1419 \\
\cline { 2 - 6 } & -0.0195 & 0.1596 & 0.3240 & 0.1536 & 0.0804 \\
\cline { 2 - 6 } & 0.0048 & 0.3771 & 0.1962 & 0.3486 & 0.1395 \\
\cline { 2 - 6 } & 0.0000 & 0.1548 & 0.2205 & 0.0681 & 0.0069 \\
\cline { 2 - 6 } & -0.006 & 0.1506 & 0.2940 & 0.0072 & 0.006 \\
\cline { 2 - 6 } & -0.0321 & 0.2427 & 0.2442 & 0.1377 & -0.0363 \\
\hline \multirow{2}{*}{ Mean } & 0.0033 & 0.2305 & 0.2433 & 0.1423 & 0.0436 \\
\hline SD & 0.0387 & 0.1505 & 0.0720 & 0.1092 & 0.0371 \\
\hline
\end{tabular}

\section{Discussion}

The intervertebral discs are structures with a peripheral portion surrounded by a ring of fibrous cartilaginous tissue (fibrous annulus), whereas its center is occupied by a tissue of embryonic origin rich in glycosaminoglycans (especially hyaluronic acid) and water (nucleus pulposus). Thus, this morphological and biochemical constitution allows the discs between the vertebral bodies to act as a complex hydraulic system, that absorbs shocks and provides a transient compression or distension. In addition, the intervertebral discs allow the movement of the vertebral column and can be compared to a mechanical shock absorber [16].
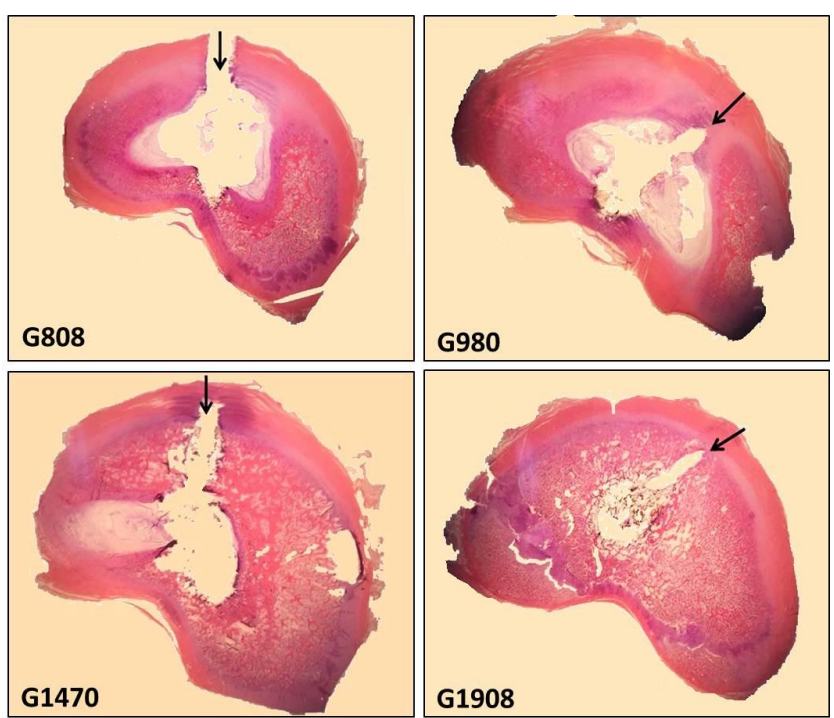

Figure 3 Microphotographs from intervertebral discs after laser irradiation showing damaged tissues (arrows).

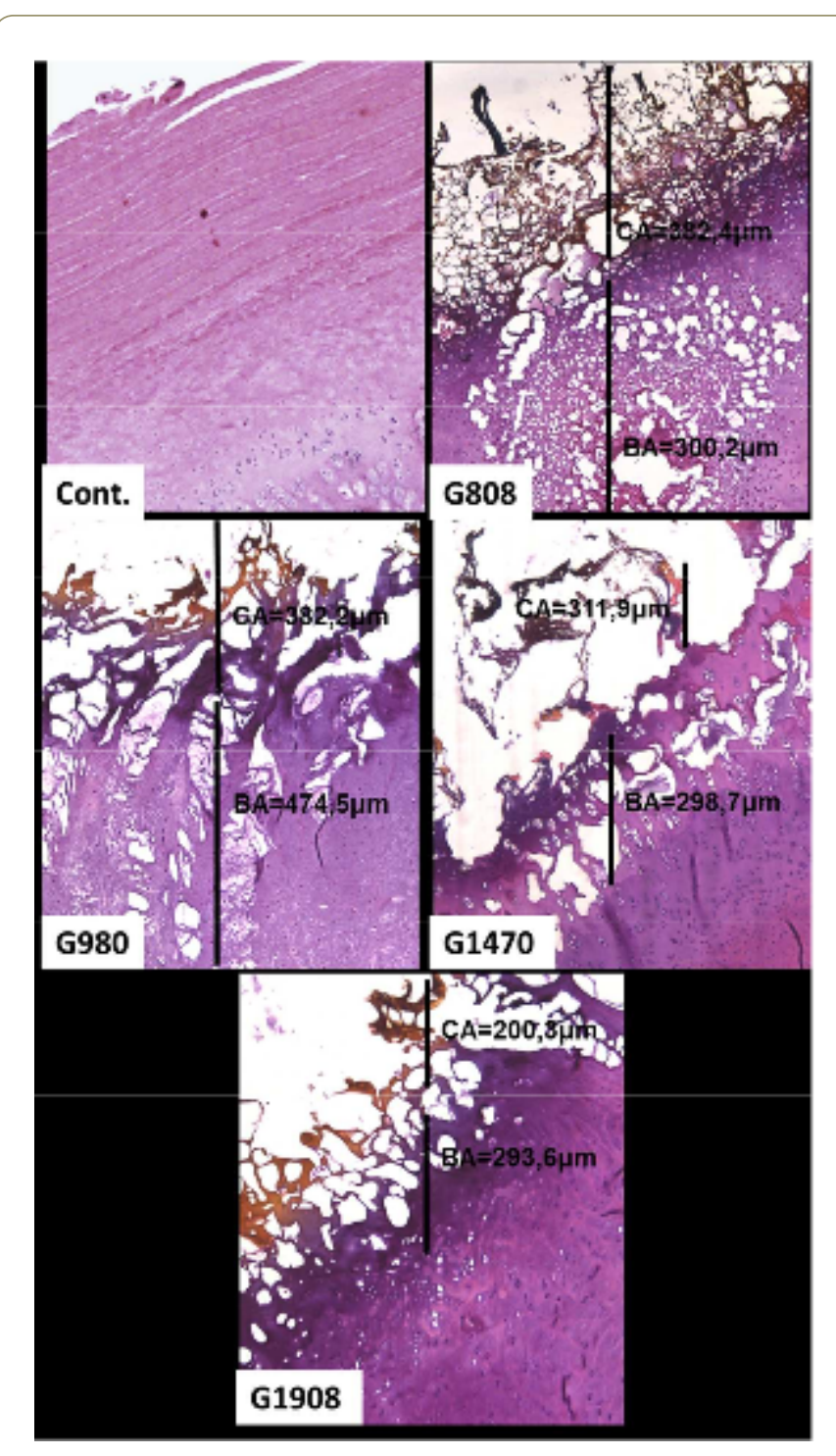

Figure 4 Photomicrographs of H.E stained histological sections showing intervertebral discs regions of all experimental groups. Note the higher thickness of carbonized area in the $\mathrm{G} 980$ and G808, as compared to G1740 and G1908; also observe the higher thickness of carbonized area in the $\mathrm{G} 980$ and G808, as compared to G1740 and G1908; also observe the higher thickness of bubble area (BA) in the G980, as compared to the other groups, magnification: $100 \mathrm{x}, 72 \times 128 \mathrm{~mm}(300 \times 300 \mathrm{DPI})$.

However, degeneration of the collagen fibers of the cartilaginous tissue may occur, leading to a rupture of this region and an extravasation of the nucleus pulposus into the medullary canal with compression of the spinal cord, as well as of the roots of the nerves. In these cases of injury, there is a surgical indication for removal of the extruded tissue.

Thus, the surgeon's main task is to use a less invasive surgical approach to relieve the patient's suffering, thus avoiding injuries adjacent to the anatomical limits of the disc. There are several surgical techniques for the removal of these compression elements; however, all approaches present surgical risks $[17,18]$. Few surgical routes have traditionally 
been efficient for the treatment of intervertebral disc lesions since they do not consider the position and extent of herniations, which should influence the effectiveness and safety of each approach. Adequate mastery of traditional approaches still represents a basic requirement, but the introduction of combined procedures and the progressive integration of new techniques, such as the endoscopic, represent both the next challenge and the future opportunity to greatly improve the surgical arsenal in these pathologies.

In this sense, our objective was to develop an anatomicalradiological study that aims to show how laser radiation can be useful in correcting this type of surgery, without causing as much damage to adjacent tissues. However, there are still doubts whether the percutaneous laser discectomy (PLDD) presents real effectiveness and what would be the best wavelength to be used. The search for the best wavelength that acts on the tissue of the nucleus pulposus considers the maximum absorption by the water contained in it and the less injury by carbonization, that is, less injury to the adjacent tissue. For this reason, the gold standard has been the $980 \mathrm{~nm}$ laser followed by the $1470 \mathrm{~nm}$ wavelength laser.

From the pioneering works of Nachemson [19] the literature reports that the disc behaves as a closed hydraulic system and that the vaporization of the tissue causes a negative pressure that would retract the herniated portion [20-22], even correlating the volume withdrawn with the degree of retraction [23]. Kasch et al. [24] obtained a reduction of the disc volume after high frequency (AF) application, whereas in the group subjected to nucleoplasty without AF there was an increase in volume. The increase by the insertion of the rod that would push the core out is justified, whereas the vaporization caused by the AF would pull the nucleus to the center; however, the study was carried out in intact disks.

Choy and Diwan [25] measured the intradiscal pressure variation during and after the application of $\mathrm{Nd}$ : YAG laser with an energy of $1000 \mathrm{~J}$ and found a decrease of $55.6 \%$ (in vitro) and $50 \%$ (in vivo) in the pressure with remission of symptoms. However, the main doubt remains, that is if the insertion of the needle alone causes a loss of tissue, why would not this be enough to decrease the pressure in the system? This response becomes crucial as the disc damaged to the point of containing cavities - as in the case of laser decompression - loses this closed system feature [19]. The simple removal of the material from the nucleus pulposus alone would be responsible for the decrease in pressure and justify the results already obtained by conventional techniques? Another question is whether the difference in wavelength would lead to differences in the volume of the vaporization lesion.

Comparing the laser at wavelengths of $980 \mathrm{~nm}$ and $1064 \mathrm{~nm}$ Jayasree et al. [26] concluded that there were differences in the depth of the lesion and the carbonization of the tissue. However, the data showed that there were no significant differences between the volumes and that these vary greatly. Since the remaining data were constant including the temperature, and that the vaporization rate is constant for a given type of laser, it must be inferred that what would determine the volume variation would be the wavelength used
[27]. In this case, the amount of free water in the tissue would be fundamental, as the absorption depends on the amount of water vaporized before the carbonization tissue is obtained [16].

In a previous study, Plapler et al. [15] found a smaller thermal lesion with the laser in $1908 \mathrm{~nm}$ and a sharper one at $980 \mathrm{~nm}$, where there was a greater injury to adjacent tissues. This means that, although the volume is not significantly different, the quality of the tissue was worse than with the other wavelengths. An explanation for the retraction of the nucleus pulposus would be the contraction of the tissue after the vaporization; this retraction is greater as less carbonization occurs, since carbonization stiffens the tissue. The effect of the laser would be due not to negative pressure, but to the amount of tissue retracted.

Considering these data from the literature, we wondered which wavelength would less injure the adjacent tissue, so we evaluated the lesions after laser irradiation of $808 \mathrm{~nm}, 980 \mathrm{~nm}$, $1470 \mathrm{~nm}$ and $1908 \mathrm{~nm}$, since these are the most studied wavelengths for this purpose. We used magnetic resonance and tissue morphology methodologies in this study. The volume analysis of the intervertebral discs is a quantitative method that contributes to detecting the degeneration of the intervertebral disc [28]. In addition, it provides data from the lesions of the tissues adjacent to the intervertebral disc. Based on this method, the laser at a wavelength of $1908 \mathrm{~nm}$ was considered the most efficient for the vaporization of the nucleus pulposus, followed by the laser wavelengths of 1470 $\mathrm{nm}, 808 \mathrm{~nm}$ and $980 \mathrm{~nm}$ and showed to be useful for the nucleotomy laser procedure.

Ren et al. [29] in a retrospective study with 22 patients, showed that the Nd:YAG laser nucleation $(\lambda=1064 \mathrm{~nm})$ did not cause reduction of the intervertebral space, and there was improvement of the lumbar pain and decrease of the herniated disc, which was evidenced by evaluation of magnetic resonance imaging. Due to its large amount of water and little pigment, the nucleus pulposus provides large absorption peaks around 980, 1064, 1470, $1910 \mathrm{~nm}, 2000 \mathrm{~nm}$ and $10600 \mathrm{~nm}$. The ND:YAG laser $(\lambda=1064 \mathrm{~nm})$, due to its specificity, and the diode laser $(\lambda=808 \mathrm{~nm}$ and $\lambda=980 \mathrm{~nm})$ are the most used devices to achieve this objective, due to their efficiency and easy transportation and handling. The Ho:YAG laser $(\lambda \cong 2.0$ $\mu \mathrm{m})$ would be the ideal choice in terms of maximum absorption values [30]. However, the power required for its action is very high and generates an excessive amount of heat. Therefore, its use may be risky in relation to the lesions resulting from the increase in the temperature in the nerve roots and requires concomitant irrigation [31].

Water is the first element for the absorption of the laser, followed by absorption by the carbonized tissue. The higher is the affinity for water, the lower is the formation of the carbonization zone, which, therefore, results in fewer injuries to the tissue adjacent to the irradiated area. We expected that the $980 \mathrm{~nm}$ laser, which has a greater affinity for water than the $808 \mathrm{~nm}$ laser, could produce better results. However, we observed that the $980 \mathrm{~nm}$ laser caused larger lesions and 
formation of more carbonized tissue in the same physical conditions as the $808 \mathrm{~nm}$ laser.

Plapler et al. [15] carried out a similar study using columns that were previously frozen because of the long time elapsed between sample collection and the irradiation procedure and it was, therefore, necessary to thaw them. Although the tissues remained apparently intact after this process, the water contained in them could have been modified by temperature. In addition, the pieces were irradiated at room temperature, and the defrosting process could have affected the amount of uncured water in the tissues. The data obtained on the discs in which the laser was not applied showed that the deterioration of the samples was higher. They observed that by modifying the structure of the tissue by evaporating the water and forming a carbonized tissue with a lower aqueous content, the application of the laser reduced the degradation of the tissue due to the thaw.

This fact justified some measurements of the greater depth of injury in the control group compared to the laser group. They could be caused by tissue deterioration, which would increase the size of the lesions, but without causing residual damage. In the present study performed in tissue at room temperature, without freezing, no different characteristics were observed in the lesions that were found in the previous study. As we cannot ascertain the amount of free water in the tissue, the findings obtained suggest that the amount of free water did not interfere with the characteristics of the lesions.

In addition to magnetic resonance imaging, we evaluated by a histological method what kind of lesions occurred at these same wavelengths. Thus, we observed in the groups irradiated with $808 \mathrm{~nm}$ and $980 \mathrm{~nm}$ greater thickness of carbonized area, in comparison to the other groups. In addition to the larger carbonized area, the G980 group had a higher bubble area thickness when compared to the other groups. However, the lesions observed in groups G808 and G980, although more pronounced, were more localized and restricted to the nucleus pulposus. These data indicate that the carbonized and bubble regions caused by lasers of wavelengths of $808 \mathrm{~nm}$ and 980 $\mathrm{nm}$, despite being observed in the histology are not detected by magnetic resonance, justifying the fact that we observed magnetic resonance in the minor area injured in these groups.

MR showed a smaller lesion of structures adjacent to the intervertebral disc in G1470 and G1908 groups, matching the histological analysis that showed that these groups presented greater preservation of nucleus pulposus and fibrous ring, wherein we observed lower thickness of carbonized and bubble areas. A possible explanation for this result is based on the observation that the laser with wavelengths of $1470 \mathrm{~nm}$ and $1908 \mathrm{~nm}$ has greater affinity for water (abundant in the nucleus pulposus), promoting greater evaporation of the water with less ablation [15,21]. The histological findings also corroborate the previous study of Cselik et al. [16] that showed through magnetic resonance that the laser at $1470 \mathrm{~nm}$ has a more comprehensive action, whereas the laser at $980 \mathrm{~nm}$ has a more focal action, causing more tissue ablation.
Another point to be discussed in the clinical work is the fact that the fibrous annulus, in the case of a protrusion, is found to have collagen fibers ruptured and therefore less exposed to the action of a possible negative pressure. The tissue retraction, however, would bring the attached fibers of the ring to inside. These assumptions still need to be confirmed.

The advantages of laser surgery with this minimally invasive method would be the possibility of performing the procedure in an outpatient setting, with the quick resolution of pain and recovery time [6], implying a lower cost and an earlier return to work and usual activities.

It is necessary to rethink the mechanism of action in the retraction of the protruding tissue, that would be due to retraction of the core tissue adjacent to the vaporization zone and not to decreasing pressure. With further studies and refinement of the PLDD technique, it is expected that its application will reach a greater number of patients in the future, improving the prognosis of patients who would be eligible for minimally invasive surgery.

\section{Conclusion}

In conclusion, our data indicate that the injuries caused by the application of the laser of $808 \mathrm{~nm}$ and $980 \mathrm{~nm}$ to the intervertebral disc are more intense, but more localized, compared to the application of the laser of $1470 \mathrm{~nm}$ and 1908 $\mathrm{nm}$. Moreover, the volume of the lesions caused by the laser of wavelength $808 \mathrm{~nm}$ and $980 \mathrm{~nm}$ was larger than that found in the irradiated disks with $1470 \mathrm{~nm}$ and $1908 \mathrm{~nm}$.

\section{References}

1. Choy DSJ (2004) Percutaneous laser disc decompression: A 17years' experience. Photomed Laser Surg 22: 407-410.

2. Ars MP, Peul WC, Brand R, Koes BW, Thomeer RT (2006) Costeffectiveness-effectiveness of microendoscopic discectomy versus conventional open discectomy in the treatment of lumbar disc herniation: a prospective randomized controlled trial. BMC Musculoskel Dis 7: 42-47.

3. Choy DSJ, Hellinger J, Hellinger S, Tassi GP, Lee SH (2009) 23rd Anniversary of Percutaneous Laser Disc Decompression (PLDD). Photomed Laser Surg 27: 535-538.

4. Schenk B, Brouwer P, Peul W, Van Buchem M (2006) Percutaneous laser disc decompression: A review of the literature. Am J Neuroradiol 27: 232.

5. Schenk B, Brouwer P, Peul W, Van Buchem M (2006) Experimental basis of percutaneous laser disc decompression (PLDD): A review of literature. Laser Med Sci 21: 245.

6. Gupta A, Bodhey N, Jayasree R, Kapilamoorthy T, Kesavadas C, et al. (2006) Percutaneous laser disc decompression: Clinical experience at SCTIMST and long term follow up. Neurol India 54: 164-167.

7. Menchetti P, Bini W, Canero G, Menotti F (2001) Percutaneous laser diode discectomy: Multicenter study at 4 years follow up. Internet J Min Invas Spin Technol 33: 115-122.

8. Morelet A, Boyer F, Vitry F, Ackah-Miezan S, Berquet R, et al. (2009) S. Efficacy of percutaneous laser disc decompression for 
radiculalgia due to lumbar disc hernia (149 patients). Presse Med 36: 1577.

9. Choy DSJ, Tassi GP, Hellinger J, Hellinger S, Lee SH (2009) Twenty-three years of percutaneous laser disc decompression (PLDD): State of the art and future prospects. Med Laser Appli 24: 147-157.

10. Choy DSJ (2004) Successful emergency percutaneous laser disc decompression. Photomed Laser Surg 22: 171-172.

11. Knappe V, Frank F, Rohde E (2004) Principles of lasers and biophotonic effects. Photomed Laser Surg 22: 411-417.

12. Goldman L, Rockwell RJ (1996) Laser action at cellular level. JAMA-J Am Med Assoc 198: 173.

13. Iwatsuki K, Yoshimine T, Umegaki M, Yoshimura K, Ohnishi Y, et al. (2011) Percutaneous diode laser irradiation for lumbar discogenic pain: A clinical study. Photomed Laser Surg 29: 459-463.

14. Hellinger J, Linke R, Heller HA (2001) Biophysical explanation for $\mathrm{Nd}$ :YAG percutaneous laser disc decompression success. J Clin Laser Med Surg 19: 235-238.

15. Plapler, H, Mancini MW, Sella VR, Bomfim FR (2016) Evaluation of different laser wavelengths on ablation lesion and residual thermal injury in intervertebral discs of the lumbar spine. Laser Med Sci 31: 421-428.

16. Cselik Z, Aradi M, Von Jako RA, Lelovics Z, Juhasz I, et al. (2012) Impact of infrared laser light-induced ablation at different wavelengths on bovine intervertebral disc ex vivo: Evaluation with Magnetic Resonance Imaging and Histology. Lasers Surg Med 44: 406-412.

17. Cong L, Zhu Y, Tu GA (2016) meta-analysis of endoscopic discectomy versus open discectomy for symptomatic lumbar disk herniation. Eur Spine J 25: 134-143.

18. Zhao P, Tian Q (2009) The history and principle of spinal manipulation in the treatment of lumbar intervertebral disc herniation. Zhongguo Gu Shang 22: 276-278.

19. Nachemson A (1960) Lumbar intradiscal pressure. Experimental studies on post-mortem material. Acta Orthop Scand 43: 1-104.
20. Case RB, Choy DSJ, Altman P (1995) Change of intradisc pressure versus volume change. J Clin Laser Med Surg 13: 143-147.

21. Choy DSJ (1987) Percutaneous laser nucleolysis of lumbar disks. N Engl J Med 317: 771-772.

22. Choy DSJ, Ascher PW, Saddekni S (1992) Percutaneous laser disc decompression: A new therapeutic modality. Spine 17: 949-956.

23. Choy D, Michelsen J, Getrajdman D (1992) Percutaneous laser disc decompression: an update. J Clin Laser Med Surg 10: 177-184.

24. Kasch R, Mensel B, Florian S, Ruetten S (2012) Disc volume reduction with percutaneous nucleoplasty in an animal model. PLOS ONE 7: e50211 p.

25. Choy DSJ, Diwan S (1992) In vitro and in vivo fall of intradiscal pressure with laser disc decompression. J Clin Laser Med Surg 10: 435-437.

26. Jayasree R, Gupta A, Bodhey N, Mohanty M (2009) Effect of 980$\mathrm{nm}$ Diode laser and 1064- $\mathrm{nm} \mathrm{Nd}$ :YAG LASER on the Intervertebral Disc - In vitro and in vivo Studies. Photomed \& Laser Surg 27: 547-552.

27. Jacques $\mathbf{S}(1998)$ Continuous laser ablation of carbonized tissue: Simple rules. Oregon Medi Laser Cent.

28. Yang S, Liu Y, Bao Z, Zou JHY (2017) Comparison of adjacent segment degeneration after nonrigid fixation system and posterior lumbar interbody fusion for single-level lumbar disc herniation: A new method of MRI analysis of lumbar nucleus pulposus volume. J Invest Surg 19: 1-6.

29. Ren L, Guo H, Zhang T, Han Z, Zhang L, et al. (2012) Efficacy evaluation of percutaneous laser disc decompression in the treatment of lumbar disc herniation. Photomed Laser surg 31: 174-178.

30. Patel N, Singh V (2018) Percutaneous lumbar laser discectomy: Literature review and a retrospective analysis of 65 cases: Photomed Laser Surg 36: 518-521.

31. Casper G, Hartman V, Mullins L (1996) Results of a clinical trial of the holmium:YAG laser in disc decompression utilizing a sidefiring fiber: a two-year follow-up. Lasers Surg Med 19: 90-96. 